\title{
Ibuprofen Antifungal Activity on Both Planktonic and Biofilm Forms of Fluconazole-Resistant Candida spp. Strains and its Mechanism of Action Evaluated by Flow Cytometry
}

Letícia S. Sampaio ${ }^{1,2}$, Cecília R. da Silva ${ }^{1,3}$, Rosana S. Campos ${ }^{1,3}$, Francisca B.S.A. do Nascimento $^{1,2}$, João B.A. Neto ${ }^{1,2}$, Lisandra J. da Silva ${ }^{1}$, Brenda S. Gaspar ${ }^{1}$, Helaine A. Queiroz $^{1}$, Fátima D.D. Barroso ${ }^{1}$, Jacó R.L. Mesquita ${ }^{7}$, Manoel O. de Moraes ${ }^{4}$, Bruno C. Cavalcanti $^{4}$, Hemerson I.F. Magalhães ${ }^{5}$, Iri S.P. Lima ${ }^{6}$ and Hélio V.N. Júnior ${ }^{1,2}$

${ }^{1}$ Department of Clinical and Toxicological Analysis, School of Pharmacy, Laboratory of Bioprospection in Antimicrobial Molecules (LABIMAN), ${ }^{2}$ Department of Pathology and Legal Medicine, School of Medicine, ${ }^{4}$ Department of Physiology and Pharmacology, Neuropharmacology Laboratory, ${ }^{6}$ Department Pharmacology, School of Medicine, Federal University of Ceará, Fortaleza, CE, Brazil

${ }^{3}$ Christus University Center, Fortaleza, CE, Brazil

${ }^{5}$ School of Pharmacy, Federal University of Paraiba, João Pessoa, PB, Brazil;

${ }^{7}$ São José Hospital, Fortaleza, CE,Brazil

*Corresponding author

\section{A B S T R A C T}

Over the past few decades, researches have reported an increased incidence of invasive candidiasis and suggested that the majority of infections produced by this pathogen are

Keywords

Candida spp.,

Resistance,

Ibuprofen, Biofilm, Apoptosis

\section{Article Info}

Accepted:

16 February 2018

Available Online:

10 March 2018 associated with biofilm growth, which are more resistant to antimicrobial agents than planktonic cells. In addition to these problems, there are few antifungal agents available and it is necessary the development of novel therapeutic strategies. In that context, this study aimed to assess the antifungal potential of ibuprofen against fluconazole-resistant Candida spp. planktonic and biofilm forms proposing a new view to the drug that are used with other therapeutic indications. After $24 \mathrm{~h}$, the fluconazole-resistant Candida spp. strains showed minimum inhibitory concentration (MIC) in the ranges of $1.5-3 \mathrm{mg} / \mathrm{mL}$ for ibuprofen by the broth microdilution method (M27-A3). According to our data by flow cytometry, ibuprofen cause fungal death after damaging the plasma and mitochondrial membrane associated to an increase of phosphatidylserine externalization which activates apoptotic signaling pathways. Regarding biofilm-forming isolates, ibuprofen promotes a reduction of viability cell in mature biofilm of Candida spp. $(\mathrm{p}<0.05)$. Therefore, it was concluded that ibuprofen is capable of inhibit the growth in vitro of Candida spp. fluconazole-resistant, both in planktonic as biofilm form, inducing cell death by apoptosis. 


\section{Introduction}

In recent years, the treatments used for HIV/AIDS and the medical advances in Intensive Care Units (ICUs) and in organ transplantation have led to an increase in the life expectancy of patients. However, associated with these advances in medicine, there has been an increased incidence of opportunistic infections, especially fungal infections, with the main pathogenic fungi belonging to the genus Candida, responsible for $70 \%$ to $90 \%$ of cases of invasive fungal infections, being associated with high mortality rates (Yapar, 2014; Delaloye and Calandra, 2014).

Currently, the increased incidence of Candida non-albicans as well as its potential to develop resistance to antifungal drugs have been reported, thus representing a challenge for clinical management. This change in the epidemiology of Candida spp. has been partially related to the widespread use of fluconazole, an inexpensive antifungal drug and available for oral administration, thus promoting selection of strains less sensitive to this antifungal agent (Garnacho-Montero et al., 2010; Sanguinetti et al., 2015; Whaley et al., 2017).

Candidemia is often related to the biofilm growth of Candida spp. in medical devices such as central venous catheter and those used for hemodialysis (Pierce et al., 2015).These infections associated with devices with biofilm have a strong impact on patient management and hospital expenses, since once the biofilm infection is settled, the treatment becomes more difficult, increasing hospitalization time and patient-related hospital costs (Rajendran et al., 2016).

Faced with this problem, it is necessary to search for new therapeutic alternatives. In this context, it may be highlighted the redirection of drugs approved by the Food and Drug Administration (FDA). These drugs have well characterized pharmacological and toxicological properties, thus reducing the time and the cost for the development of a new medicine (Siles et al., 2013). The literature has reported the antifungal activity of ibuprofen, a nonsteroidal antiinflammatory drug (NSAID) whose mechanism of action is inhibition of the enzyme cyclooxygenase (COX) and consequent inhibition of the synthesis of prostaglandin (PGD2, PGF2, PGE2, PGI2) and thromboxane (TX) (Pina-Vaz et al., 2000, Alem and Douglas., 2004, Goodman and Gilman's, 2012).

The present work aimed to study the antifungal action of ibuprofen against both planktonic and biofilm forms of fluconazoleresistant Candida spp. strains and, by means of flow cytometry and comet assay techniques, to evaluate the possible mechanisms involved in cell death.

\section{Materials and Methods}

\section{Yeast strains}

Ninefluconazole-resistant clinical strains of $C$. albicans, C. tropicalis and C. parapsilosis molecularly identified and two ATCC strains (Candida parapsilosis ATCC 22019 and Candida krusei ATCC 6258) were used. These strains are from the yeast collection of the Laboratory of Bioprospection in Antimicrobial Molecules (LABIMAN/ FF/UFC).

\section{In vitro antifungal activity}

The drug was tested according to the document M27-A3 using RPMI broth $(\mathrm{pH}$ 7.0) buffered with 0.165 M MOPS (Sigma Chemical, St. Louis, MO). Ibuprofen (IBU; Sigma Chemical, St. Louis, MO) was 
dissolved in distilled water and tested at concentrations ranging from $0.058-3 \mathrm{mg} / \mathrm{mL}$. The yeasts and compound were incubated in 96-well culture plates at $35^{\circ} \mathrm{C}$ for $24 \mathrm{~h}$ and by CLSI recommendation the results were analysed visually. The minimum inhibitory concentration (MIC) of each compound was determined as the concentration that inhibited $50 \%$ of fungal growth. The strains $C$. parapsilosis ATCC 22019 and C. krusei ATCC 6258 were used as controls (CLSI, 2012).

\section{Cell treatments and preparation of yeast suspensions}

To assess cell density, mitochondrial transmembrane potential, annexin $\mathrm{V}$ staining and to detect reactive oxygen species (EROs) generation, one representative FLC-resistant strain of each species of Candida spp (Table 1) was exposed for $24 \mathrm{~h}$ to various concentrations (MIC, $2 \times$ MIC and $4 \times \mathrm{MIC}$ ) of ibuprofen. Cells treated with FLC $(64 \mu \mathrm{g} / \mathrm{mL})$ or amphotericin B - ampho B $(4 \mu \mathrm{g} / \mathrm{mL})$ were included for comparison. All the tests were performed in triplicate in three independent experiments (Andrade Neto et al., 2014).

Cell suspensions were prepared from cultures in the exponential growth phase. The cells were collected, washed, re-suspended and adjusted to $10^{6}$ cells/mL in HEPES buffer $(\mathrm{pH}$ 7.2) supplemented with $2 \%$ glucose. Ampho B (Sigma Chemical) was used as a cell death control (Andrade Neto et al., 2014).

\section{Evaluation of cell density}

Cell density of the fungal strain was evaluated by the exclusion of $2 \mathrm{mg} / \mathrm{L}$ propidium iodide (PI). After $24 \mathrm{~h}$ for incubation, aliquots from yeast cells with IBU, FLC, and AMPHO B were analyzed by flow cytometry. A total of 10.000 events was evaluated per experiment $(n=2)$ and cellular debris was omitted from the analysis. Cellular fluorescence was then determined by flow cytometry using a Guava EasyCyte $^{\text {TM }}$ Mini System cytometer (Guava Technologies Inc., Hayward, CA, USA) and analyzed using CytoSoft 4.1 software (Andrade Neto et al., 2014; Da Silva et al., 2016).

\section{Measurement of mitochondrial transmembrane potential $(\Delta \psi \mathrm{m})$}

$\Delta \psi \mathrm{m}$ was determined by measuring rhodamine 123 dye retention by the mitochondria of yeast cells after $24 \mathrm{~h}$ of exposure. Cells were washed with phosphatebuffered saline (PBS), incubated with $5 \mathrm{mg} / \mathrm{L}$ rhodamine 123 at $37^{\circ} \mathrm{C}$ for $30 \mathrm{~min}$ in the dark, and then washed twice with PBS. Fluorescence was measured by flow cytometry (Guava EasyCyteminisystem). A total of 10.000 events were evaluated per experiment $(n=2)$, and cellular debris was omitted from the analysis (Andrade Neto et al., 2014).

\section{Annexin V staining}

Yeast cells were harvested by centrifugation and digested with $2 \mathrm{mg} / \mathrm{mL}$ zymolyase $20 \mathrm{~T}$ (Seikagaku Corp., Japan) in potassium phosphate buffer (PPB, $1 \mathrm{M}$ sorbitol, $\mathrm{pH}$ 6.0) for $2 \mathrm{~h}$ at $30{ }^{\circ} \mathrm{C}$. The protoplasts were then stained with FITC-labelled Annexin V and PI using a FITC-Annexin V apoptosis detection kit (Guava Nexin Kit, Guava Technologies).

Subsequently, the cells were washed with $\mathrm{PPB}$, incubated for $20 \mathrm{~min}$ in Annexin binding buffer containing $5 \mu \mathrm{L} / \mathrm{mL}$ FITCAnnexin $\mathrm{V}$ and $5 \mu \mathrm{L}$ of PI and analyzed by flow cytometry (Guava EasyCyte ${ }^{\mathrm{TM}}$ Mini System). For each experiment $(n=2)$, 10.000events were evaluated and cell debris was omitted from the analysis (Andrade Neto et al., 2014). 


\section{Detection of reactive oxygen species (ROS)}

ROS produced over a $24 \mathrm{~h}$ culture period were detected by incubating the cells with 20 $\mu \mathrm{M}$ CM- $\mathrm{H}_{2}$ DCFDA [5-(and-6)-chloromethyl2',7'-dichlorodihydrofluorescein diacetate acetyl ester] for $30 \mathrm{~min}$ in the dark at $35^{\circ} \mathrm{C}$. Subsequently, the cells were harvested by centrifugation, washed with PBS, resuspended in the same buffer and analyzed by flow cytometry (Guava EasyCyte Mini System). $\quad \mathrm{CM}-\mathrm{H}_{2}$ DCFDA readily diffuses through the cell membrane and is hydrolyzed by intracellular esterases to form nonfluorescent DCFH $\left(2^{\prime}, 7^{\prime}\right.$-dichlorodihydrofluorescein), which is then rapidly oxidized to highly fluorescent DCF $\left(2^{\prime}, 7^{\prime}\right.$ dichlorofluorescein) by a broad range of intracellular oxidative stresses other than $\mathrm{H} 2 \mathrm{O} 2$. The fluorescence intensity of DCF is proportional to the amount of ROS formed intracellularly (Andrade Neto et al., 2014; Da Silva et al., 2016).

\section{Yeast comet assay}

This assay was performed essentially as described by Da Silva et al.(2016). For each experimental group, it was under analysis images obtained by fluorescence microscopy of 100 randomly selected cells (50 cells from each of 2 replicate slides).

The cells were scored visually and depending on their tail size they were assigned to one of five classes (from undamaged [class 0] to maximally damaged [class 4]), and a damage index value was calculated for each sample of cells. The damage index values, thus, ranged from 0 (completely undamaged: 100 cells $x$ ) to 400 (maximum damage: 100 cells $\mathrm{x}$ 4). The tailed cells were taken as an indicator of DNA damage and its frequency was calculated based on the numbers of cells with tails (DNA strand breaks) and without them (Da Silva et al., 2016).

\section{Formed biofilm}

Candida spp. biofilm was formed on 96-well plates $\left(1.0 \times 10^{6}\right.$ cells/well) (Table 1$)$. The plates were incubated at $35{ }^{\circ} \mathrm{C}$ for $24 \mathrm{~h}$ and after this time, the wells were washed three times with PBS and $200 \mu \mathrm{L}$ of ibuprofen solution, ranging from 0.75 to $60 \mathrm{mg} / \mathrm{mL}$, was added to each well containing viable $24 \mathrm{~h}$ biofilm. The plates were incubated at $35{ }^{\circ} \mathrm{C}$ for $24 \mathrm{~h}$. The measurement of the metabolic activity of biofilm cells was evaluated using the MTT colorimetric assay and the readings were performed in a microplate reader at 540 nm (Pierce et al., 2008).

\section{Statistical analysis}

In vitro susceptibility experiments were repeated three times on different days and geometric means were used to compare the MIC values. The data obtained from the flow cytometry and alkaline comet assays were compared using a one-way analysis of variance (ANOVA) followed by the Newman-Keuls test $(\mathrm{p}<0.05)$. Mean absorbance values from the biofilm formation assay were compared using one-way ANOVA followed by the Tukey test ( $\mathrm{p}<0.05)$.

\section{Results and Discussion}

Initially, the antifungal activity of ibuprofen against fluconazole-resistant strains of Candida spp. was evaluated and concentrations between $1.5-3 \mathrm{mg} / \mathrm{mL}$ could inhibit $50 \%$ of the fungal growth of $C$. albicans, C. tropicalis, C. parapsilosis (Table 1). In accordance with our result, a study by Pina-Vaz et al., (2000) evaluated the antifungal activity of ibuprofen, that showed $80 \%$ growth inhibition of Candida spp. resistant and sensitive to fluconazole at concentrations ranging from 1 to $3 \mathrm{mg} / \mathrm{mL}$. Based on these findings, flow cytometry assays and comet assay techniques were 
performed with the purpose of suggesting possible mechanisms of action of ibuprofen, as well as to analyze if cell death occurs due to apoptosis of strains of Candida spp. One strain of each species ( $C$. albicans, $C$. tropicalis and $C$. parapsilosis) was selected to observe if there were behavioral differences between species when in contact with ibuprofen.Fluconazol was used with negative control and there wasn't significant alterations when the fluconazole-resistant strains were treated with this drug in comparison to untreated cells $(p>0.05)$.

Cell death by apoptosis can be activated in two ways: intrinsic pathway, with mitochondrial involvement and induced mainly by cellular damage, such as DNA damage and oxidative stress; and extrinsic pathway, with the participation of a specific receptor that promotes the direct activation of the caspase cascade, leading to cell destruction (Bayles et al., 2014).

In that context, initially, the cells were treated with ibuprofen at different concentrations (MIC, 2xMIC, 4xMIC) and submitted to flow cytometry techniques to verify: cell density, alteration of the mitochondrial membrane potential, production of reactive oxygen species (ROS) and externalization of phosphatidylserine.

Cell density was evaluated using the marker propidium iodide (PI), which binds to cellular DNA when there is membrane damage, thus emitting a high fluorescence; when there is no membrane damage, this marker cannot enter and emits a lower fluorescence (Mackilis and Madison, 1990; Andrade Neto et al., 2014). In this assay, a reduction was observed in the number of viable cells, related to the increase of ibuprofen concentration for the three species analyzed (Figure 1), thus suggesting the fungicidal activity of this drug at the concentrations evaluated. Pina-Vaz et al.,
(2000) investigated the mechanism of action of ibuprofen and showed that this drug promotes damage to the plasma membrane of Candida albicans at concentrations of 10-20 $\mathrm{mg} / \mathrm{mL}$ after exposure for 5-30 minutes. De Quadros et al., (2011) investigated mechanism of action of ibuprofen and other NSAIDs (aspirin, indomethacin and sodium salicylate) in Candida spp. and they suggested that ibuprofen caused damage to the cell membrane of $C$. albicans.

Mitochondrial depolarization is an event that may indicate the initiation of the apoptotic process by the intrinsic pathway (Bonnet et al., 2007). In this study, there was no significant reduction in the number of viable cells when the fluconazole-resistant strains were treated with the azole in comparison to untreated cells $(p>0.05)$. In contrast, it was observed an increase in mitochondrial depolarization with increasing concentration of ibuprofen (Figure 2), suggesting the beginning of the apoptotic process for the three selected strains of $C$. albicans, $C$. tropicalis and $C$. parapsilosis. In this context, a study by Sanz-Blasco et al., (2008) showed that, at very low concentrations $(1 \mu \mathrm{M})$, ibuprofen and other NSAIDs caused mitochondrial depolarization of cerebellar granule cells. Another study, by Moorthy et al., (2008), showed that ibuprofen promotes morphological changes in the mitochondria of rats liver cells that were treated with 10 $\mathrm{mg} / \mathrm{kg}$ for 15 days.

The externalization of phosphatidylserine to the cell surface corresponds to one of the first apoptotic events, indicating that the cell is phagocytosed by macrophages (Engeland et al., 1998). Its determination is performed using annexin $\mathrm{V}$, which is a calciumdependent protein capable of binding externalized PS in the cell that is in the early stages of apoptosis (Liu et al., 2009). In the present work, ibuprofen promoted increased 
PS externalization in the three selected strains, at the three concentrations used, suggesting that the strains were in the process of initial apoptosis. The treatment of fluconazole-resistant cells with the ibuprofen (4xMIC) clearly induced cell death in a similar way to what was found in cells treated with amphotericin $\mathrm{B}$, which was used as a positive control (Figure 3). Redpath et al., (2009) have demonstrated from the externalization of phosphatidylserine that ibuprofen at $10 \mathrm{mM}$ induces apoptosis in human cutaneous cell lines HBL, corroborating with our results.

This study also evaluated the production of reactive oxygen species and DNA damage. As shown in Figure 4, there was an increasing in the generation of ROS when the yeast cells were exposed to increasing concentrations of ibuprofen. Figure 5 shows that regarding the MIC concentration there wasn't a significant DNA damage in the cells tested, but with an increase in concentration there was an increase in the frequency of damage $(\mathrm{p}<0.05)$. Ibuprofen is a derivative of propionic acid and a common feature of such derivatives is the ability to generate reactive oxygen species (ROS) in the presence of light. These compounds are photoactive and cause the DNA molecule to become sensitive to damage after exposure to light (Adachi et al., 2007). Husain et al., (2015) demonstrated that the generation of ROS by ibuprofen in the presence of light is dependent on the concentration of ibuprofen, also observing the interaction of this drug with DNA (Fig. 6).

Biofilm formation confers antifungal resistance to microorganisms which are associated. Thus, the capacity of Candida spp. to form drug-resistant biofilms is an important factor that contributes to the therapeutic failure and therefore the search for new antifungals, mainly targeting the biofilm, becomes fundamental (Pierce et al., 2015).

Table.1 The effects of ibuprofen against FLC-resistant strains of Candida spp.

\begin{tabular}{|c|c|c|}
\hline Strain & $\begin{array}{c}\mathrm{N}^{0} \text { Genbankof the ITS/5.8S } \\
\text { sequence }\end{array}$ & MIC (mg/mL) \\
\hline & & IBU \\
\hline C.tropicalis 1 & KF616840 & 3 \\
\hline C.tropicalis $2 * * *$ & AB861490 & 3 \\
\hline C. tropicalis 3 & KF616841 & 3 \\
\hline C. tropicalis 4 & KJ740181 & 3 \\
\hline C. tropicalis 5 & AB861491 & 3 \\
\hline C. albicans $1 * *$ & KJ740174 & 1.5 \\
\hline C. albicans $2 *$ & KJ740175 & 3 \\
\hline C. parapsilosis $1 * *$ & AB861487 & 3 \\
\hline C.parapsilosis $2 *$ & KJ740191 & 3 \\
\hline C. parapsilosis ATCC & - & 3 \\
\hline C. krusei ATCC & - & 3 \\
\hline
\end{tabular}

Minimum inhibitory concentrations (MIC) of ibuprofen against clinical FLC-resistant strains of Candida spp. The MIC was defined as the lowest concentration that produced 50\% reduction in fungal cells growth. The microdilution in broth was performed according to CLSI protocol M27-A3. The ibuprofen concentrations ranged from 0.0058 - 3 $\mathrm{mg} / \mathrm{mL}$. The MICs represent the geometric means of at least three MICs determined on different days.

* These strains were used in the biofilm formation assay.

** These strains were used to investigate the antifungal action mechanism of the ibuprofen. 
Figure.1 Effect of ibuprofen on the number of viable cells of FLC-resistant $C$. albicans, $C$. tropicalisand C. parapsilosis strains
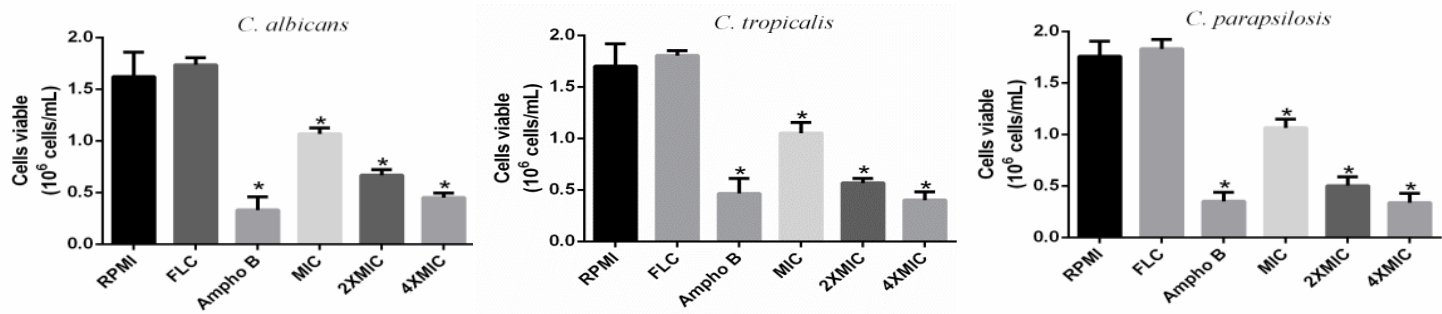

RPMI medium-control, FLC-64 $\mu \mathrm{g} / \mathrm{mL}$, Ampho B-4 $\mu \mathrm{g} / \mathrm{mL}$, Ibuprofen-MIC(3 mg/mL), 2xMIC(6 mg/mL), $4 \mathrm{xMIC}(12 \mathrm{mg} / \mathrm{mL}) . * \mathrm{p}<0.05$.

Figure.2 Assessment of the mitochondrial transmembrane potential in a representative FLCresistant strain of each species of Candida spp. treated with IBU
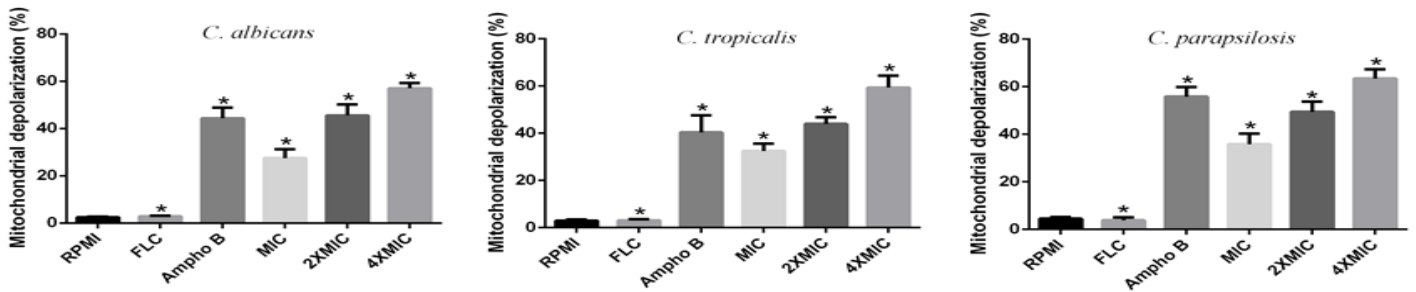

RPMI medium-control, FLC-64 $\mu \mathrm{g} / \mathrm{mL}$, Ampho B-4 $\mu \mathrm{g} / \mathrm{mL}$, Ibuprofen-MIC(3 mg/mL), 2xMIC(6 mg/mL), $4 \times \mathrm{MIC}(12 \mathrm{mg} / \mathrm{mL}) . * \mathrm{p}<0.05$.

Figure.3 Staining of phosphatidylserine with annexin V in a representative FLC-resistant strains of each species of Candida spp. treated with IBU
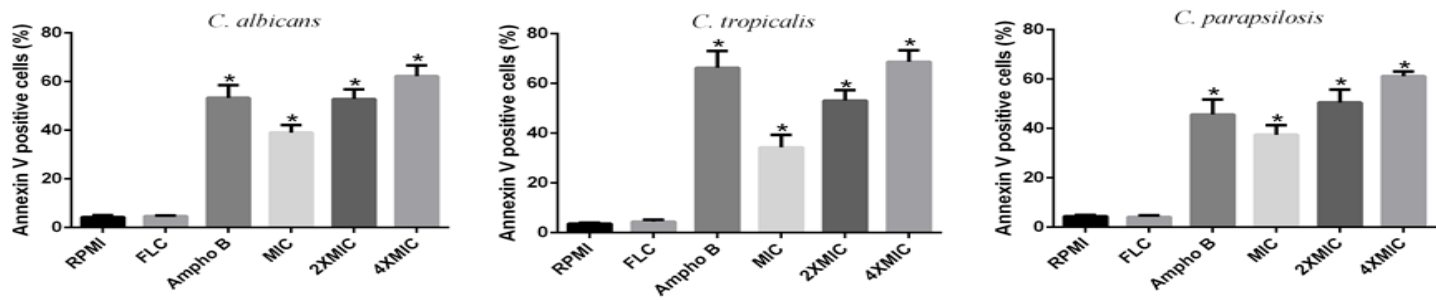

RPMI medium-control, FLC-64 $\mu \mathrm{g} / \mathrm{mL}$, Ampho B-4 $\mu \mathrm{g} / \mathrm{mL}$, Ibuprofen-MIC(3 $\mathrm{mg} / \mathrm{mL}), 2 \times M I C(6 \mathrm{mg} / \mathrm{mL})$, $4 \times \mathrm{MIC}(12 \mathrm{mg} / \mathrm{mL}) .{ }^{\mathrm{p}}<0.05$.

Figure.4 Evaluation of ROS produced in FLC-resistant $C$. albicans, $C$. tropicalis and $C$. parapsilosis strains treated with IBU
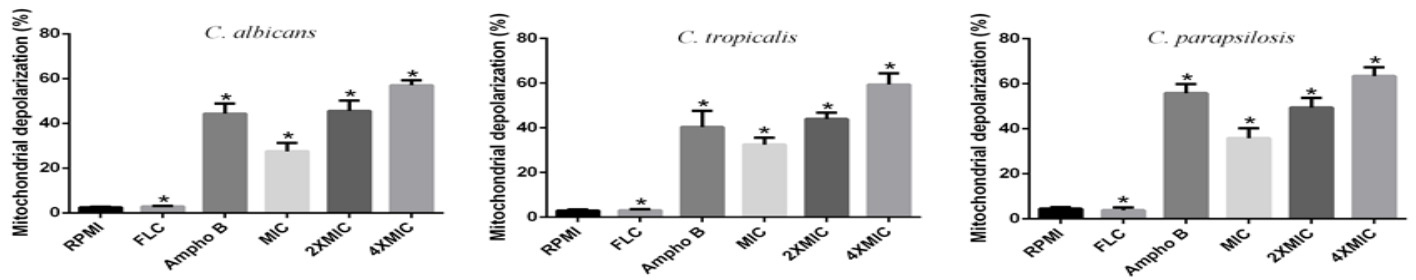

RPMI medium-control, FLC-64 $\mu \mathrm{g} / \mathrm{mL}$, Ampho B-4 $\mu \mathrm{g} / \mathrm{mL}$, Ibuprofen-MIC(3 mg/mL), 2xMIC(6 mg/mL), $4 \times \operatorname{MIC}(12 \mathrm{mg} / \mathrm{mL}) . * \mathrm{p}<0.05$. 
Figure.5 Evaluation of the DNA damage index in a representative FLC-resistant strain of each species of Candida spp. treated with IBU
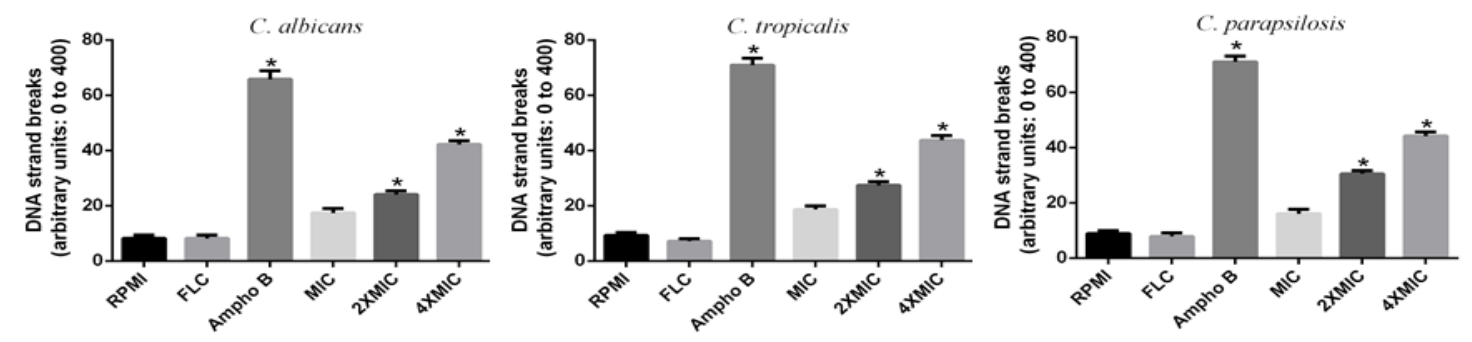

RPMI medium-control, FLC-64 $\mu \mathrm{g} / \mathrm{mL}$, Ampho B-4 $\mu \mathrm{g} / \mathrm{mL}$, Ibuprofen-MIC(3 $\mathrm{mg} / \mathrm{mL}), 2 \times M I C(6 \mathrm{mg} / \mathrm{mL})$, $4 \times \mathrm{MIC}(12 \mathrm{mg} / \mathrm{mL}) . * \mathrm{p}<0.05$.

Figure.6 Activity of ibuprofen against Candida spp. biofilm

\section{C. albicans}

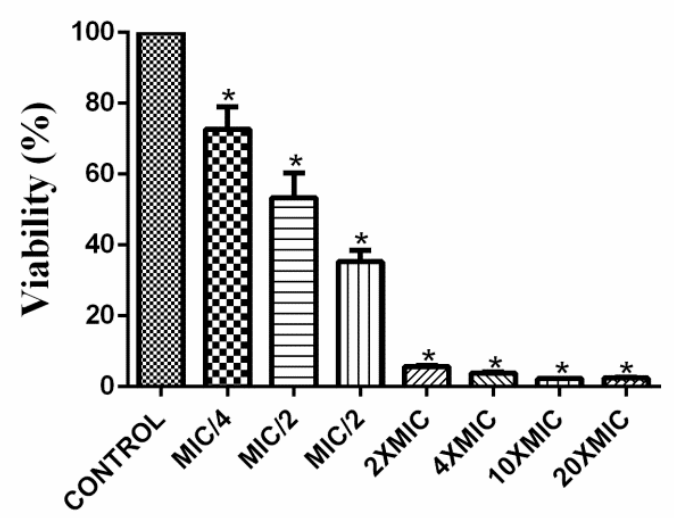

Ibuprofen $(\mathrm{mg} / \mathrm{mL})$
C. tropicalis

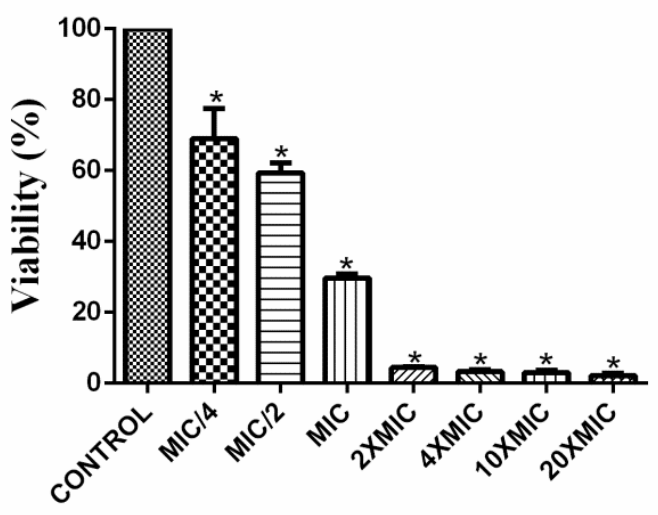

Ibuprofen (mg/mL)

C. parapsilosis

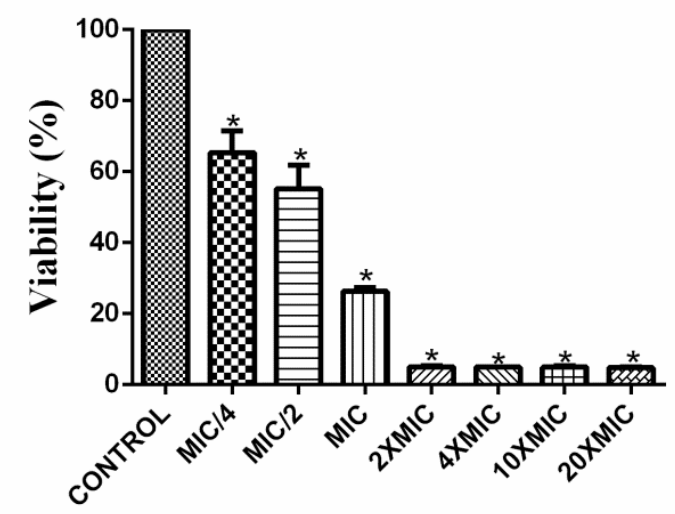

Ibuprofen $(\mathrm{mg} / \mathrm{mL})$

Ibuprofen - MIC/4 (0,75 mg/mL), MIC/L ( $1,0 \mathrm{mg} / \mathrm{mL})$, MIL ( $3 \mathrm{mg} / \mathrm{mL}), \angle X I V I C$.

(6 mg/mL), 4xMIC (12 mg/mL), 10xMIC (30 mg/mL), 20xMIC $(60 \mathrm{mg} / \mathrm{mL}) . * \mathrm{p}<0.05$. 
In this context, after verifying the activity of ibuprofen against planktonic cells of Candida spp., assays were performed when the biofilm was already formed (24h) to verify if ibuprofen would be able to unbalance its organization. Three strains of Candida spp. were selected, one of each species ( $C$. albicans, C. tropicalis, $C$. parapsilosis), which showed good biofilm formation. Inhibitory and subinhibitory concentrations of ibuprofen (MIC/4, MIC/2, MIC, 2xMIC, 4xMIC, 10xMIC and 20xMIC) were used, being verified a reduction in the viability of the formed biofilm, directly related to the increase in concentration.

The three species had a reduction of less than $50 \%$ in the viability of the biofilm when treated with MIC, a very encouraging result, since biofilms are difficult to eradicate and can be up to 2000 times more resistant than planktonic cells (Seneviratne et al., 2008).

A study by Ashraf et al., (2015) showed that $0,5 \mathrm{mg} / \mathrm{mL}$ could reduce $38 \%$ of the formed biofilm of $C$. albicans.

In this way, ibuprofen showed to be a possible prototype for the development of new antifungal drugs, being able to potentiate its activity against these microorganisms from molecular alterations.

In conclusion, ibuprofen had antifungal activity against fluconazole-resistant $C$. albicans, C. tropicalis and C. parapsilosis. Its activity may be related to promotion of mitochondrial dysfunction and externalization of phosphatidylserine suggesting that cell death occurs by apoptosis. Therefore, this study allowed a better understanding of the mechanism of action of this drug. Ibuprofen presented activity against the formed biofilm of fluconazole-resistant $C$. albicans, $C$. tropicalis and C. parapsilosis.

\section{Acknowledgments}

This work was supported by grants and fellowships from CNPq, CAPES/ Brazil, and FUNCAP/ Ceará.

\section{References}

Adachi, M., Sakamoto, H., Kawamura, R., Wang, W., Imai, K. and Shinomura, Y. 2007. Histology and Histopathology, Nonsteroidal anti-inflammatory drugs and oxidative stress in cancer cells. Histol Histopathol. 22, 437-42.

Alem, M. A. S. and Douglas, L. J., 2004. Effects of Aspirin and Other Nonsteroidal Anti Inflammatory Drugs on Biofilms and Planktonic Cells of Candida albicans. Antimicrob Agents Chemother. 48, 41-47.

Andrade Neto, J.B., da Silva, C.R., Neta, M.A.S., Campos, R.S., Siebra, J.T., Silva, R.A.C. et al., 2014. Antifungal Activity of Naphthoquinoidal Compounds In Vitro against Fluconazole-Resistant Strains of Different Candida Species: A Special Emphasis on Mechanisms of Action on Candida tropicalis. PLoS ONE. 9(5): e93698.

Ashraf, A., Yousri, F., Taha, N., El-Waly, O.A., El-Kareem Ramadan, A., Ismail, E., Hamada, R., Khalaf, M., Refaee, M., Ali, S., Madyn, A. and El-Baky, R. M. A., 2015. Effect of Some Non steroidal Anti-Inflammatory Drugs on Growth, Adherence and Mature Biofilms of Candida spp. Am J of Microbiol Res. 3, 1-7.

Bayles, K. W., 2014.Bacterial programmed cell death: making sense of a paradox. Nat Rev Microbiol. 12, 63-69.

Bonnet, S., Archer, S. L., Allalunis-Turner, J., Haromy, A., Beaulieu, C., Thompson, R., Lee, C. T., Lopaschuk, G. D., Puttagunta, L., Bonnet, S., Harry, G., 
Hashimoto, K., Porter, C. J., Andrade, M. A., Thebaud, B. and Michelakis, E. D. A., 2007. Mitochondria-K+ Channel Axis Is Suppressed in Cancer and Its Normalization Promotes Apoptosis and Inhibits Cancer Growth. Cancer Cell. 11, 37-51.

Clinical and Laboratory Standards Institute (CLSI), 2012.Reference method for broth dilution antifungal susceptibility testing of yeasts; fourth informational supplement. CLSI document M27- S4. Clinical and Laboratory Standards Institute, Wayne, PA.

da Silva, C.R., de Andrade Neto, J.B., Sidrim, J.J., Angelo, M.R., Magalhães, H.I., Cavalcanti, B.C., Brilhante, R.S., Macedo, D.S., de Moraes, M.O., Lobo, M.D., Grangeiro, T.B. and Nobre Júnior, H.V., 2013. Synergistic effects of amiodarone and fluconazole on Candida tropicalis resistant to fluconazole.AntimicrobAgentsChemoth er. 57, 1691-1700.

de Quadros, A. U., Bini, D., Pereira, P. A. T., Moroni, E. G., M. and Monteiro, C. 2011. Antifungal activity of some cyclooxygenase inhibitors on Candida albicans: PGE2-dependent mechanism. Folia Microbiol (Praha). 56, 349-352.

Delaloye, J. and Calandra, T., 2014.Invasive candidiasis as a cause of sepsis in the critically ill patient. Virulence. 5, 161169.

Engeland, M. V., Nieland, L. J. W., Ramaekers, F. C. S., Schutte, B. and Reutelingsperger, C.P.M., 1998. Annexin V-Affinity Assay: A Review on an Apoptosis Detection System Based on Phosphatidyl serine Exposure. Cytometry. 31, 1-9.

Garnacho-Montero, J., Díaz-Martín, A., García-Cabrera, E., de Pipaón, M. R. P., Hernández-Caballero, C., Aznar-Martín, J., Cisneros, J. M. and Ortiz-Leyba, C., 2010. Risk Factors for Fluconazole-
Resistant Candidemia. Antimicrob Agents Chemother. 54, 3149-3154.

Goodman and Gilman's, 2012.The pharmacological basis of therapeutics. 12th ed. New York: McGraw-Hill.

Husain, M. A., Sarwar, T., Rehman, S. U., Ishqi, H. M. and Tabish, M., 2015. Ibuprofen causes photocleavage through ROS generation and intercalates with DNA: A combined biophysical and molecular docking approach. Phys Chem.Chem Phys. 17, 1-45.

Liu, T., Zhu, W., Yang, X., Chen, L., Yang, R., Hua, Z. and Li, G., 2009. Detection of Apoptosis Based on the Interaction between Annexin $\mathrm{V}$ and Phosphatidylserine. Anal Chem. 81, 2410-2413.

Mackilis, J. D. and Madison, R. D., 1990. Progressive incorporation of propidium iodide in cultured mouse neurons correlates with declining eletrophysiological status: a fuorescence scale of membrane integrity. J Neurosci Methods. 31, 43-46.

Moorthy, M., Fakurazi, S. and Ithnin, H., 2008. Morphological Alteration in Mitochondria Following Diclofenac and Ibuprofen Administration. Pak J Biol Sci. 11, 1901-1908.

Pierce, C. G., 2008. A simple and reproducible 96 well plate-based method for the formation of fungal biofilms and its application to antifungal susceptibility testing.NIH Public Access.3, 1494- 1500.

Pierce, C. G., Srinivasan, A., Ramasubramanian, A. K., López-Ribot, J. L., 2015. From Biology to Drug Development: New Approaches to Combat the Threat of Fungal Biofilms. MicrobiolSpectr. 3, 1-18.

Pina-Vaz, C., Sansonetty, F., Rodrigues, A. G., Martinez-de Oliveira, J., Fonseca, A.F. andMardh, P. A., 2000. Antifungal activity of ibuprofen alone and in 
combination with fluconazole against Candida species. J Med Microbiol. 49, 831-840.

Rajendran, R., Sherry, L., Nile, C. J., Sherriff, A., Johnson, E. M., Hanson, M. F. Williams, C., Munro, C. A., Jones, B. J. and Ramag, G., 2016. Biofilm formation is a risk factor for mortality in patients with Candida albicans bloodstream infection-Scotland, 20122013. ClinMicrobiol Infect. 22, 87-93.

Redpath, M., Marques, C.M.G., Dibden, C., Waddon, A., Lalla, R. and MacNeil, S. 2009. Ibuprofen and hydrogel-released ibuprofen in the reduction of inflammation-induced migration in melanoma cells.Br J Dermatol. 161, 2533.

Sanguinetti, M., Posteraro, B. and LassFlöorl, C., 2015. Antifungal drug resistance among Candida species: mechanisms and clinical impact. Mycoses. 58, 2-13.

Sanz-Blasco, S., Valero, R. A., RodriguezCrespo, I.,Villalobos, C. andNunez, L., 2008. Mitochondrial Ca2+ Overload
Underlies Ab Oligomers Neurotoxicity Providing an Unexpected Mechanism of Neuroprotection by NSAIDs. PLoS ONE.3, e2718.

Seneviratne, C. J., Jin, L. and Samaranayake, L. P., 2008. Biofilm lifestyle of Candida: a mini review. Oral Dis. 14, 582-90.

Siles, S. A., Srinivasan, A., Pierce, C. G., Lopez-Ribot, J. L. and Ramasubramanian, A. K., 2013. Highthroughput screening of a collection of known pharmacologically active small compounds for identification of Candida albicans biofilm inhibitors. Antimicrob. Agents Chemother. 57, 3681-3687.

Whaley, S. G., Berkow, E. L., Rybak, J. M., Nishimoto, A. T., Barker, K. S. and Rogers, P. D., 2017. Azole Antifungal Resistance in Candida albicans and Emerging Non-albicans Candida Species. Front Microbiol. 7, 1- 12.

Yapar, N., 2014. Epidemiology and risk factors for invasive candidiasis. Ther. Clin. Risk Manag., 10, 95- 105.

\section{How to cite this article:}

Letícia S. Sampaio, Cecília R. da Silva, Rosana S. Campos, Francisca B.S.A. do Nascimento, João B.A. Neto, Lisandra J. da Silva Brenda S Gaspar Helaine A. Queiroz Fátima D.D. Barroso Jacó R.L. Mesquita, Manoel O. de Moraes, Bruno C. Cavalcanti, Hemerson I.F. Magalhães, Iri S.P. Lima and Hélio V.N. Júnior. 2018. Ibuprofen Antifungal Activity on Both Planktonic and Biofilm Forms of Fluconazole-Resistant Candida spp. Strains and its Mechanism of Action Evaluated by Flow Cytometry. Int.J.Curr.Microbiol.App.Sci. 7(03): 2063-2073. doi: https://doi.org/10.20546/ijcmas.2018.703.242 